УДК 577.175.6: 547.999.3

\title{
ОСОБЕННОСТИ ОПРЕДЕЛЕНИЯ КОНЦЕНТРАЦИИ АНТИОКСИДАНТОВ АМПЕРОМЕТРИЧЕСКИМ МЕТОДОМ
}

\section{(C) В.В. Бирюков}

Московсковский государственный университет инженерной экологии,
ул. Старая Басманная, 21/4, Москва, 105066 (Россия), e-mail: birval@rambler.ru

Проведен анализ метрологических характеристик амперометрического метода определения антиоксидантов. Показано, что амперометрический метод дает возможность корректно определять антиоксидантную активность (скорость реакции окисления). В то же время использование этого метода для косвенного определения антиоксидантной емкости (общей концентрации антиоксидантов) может быть сопряжено с существенными ошибками измерения.

Ключевые слова: антиоксиданты, антиоксидантная активность, антиоксидантная емкость, амперометрическое детектирование, скорость окисления, кинетика процесса окисления.

Для определения концентраций антиоксидантов различной природы в ряде работ предложено использовать амперометрический метод, основанный на измерении электрического тока в электрохимической ячейке, возникающего при подаче на электрод определенного потенциала [1-3]. В настоящей статье поставлена задача на основе анализа кинетики процесса окисления определить, правомерно ли использование этого метода в случаях, когда определяется суммарная концентрация разнородных антиоксидантов.

Технически измерение амперометрическим детектором проводится в непрерывном потоке раствораносителя, в который вводится импульсная доза исследуемого раствора (проточно-инжекционный метод анализа). В потоке образуется «зона образца» в виде прямоугольного импульса, которая по мере продвижения по каналу и электрохимической ячейке «размывается», так что кривая изменения концентрации измеряемого вещества во времени (или, что то же самое, по длине измерительного канала) имеет вид, напоминающий хроматографические пики. Сигнал амперометрического детектора формируется на основе вычисления площади под этой кривой. При этом время нахождения молекул вещества на поверхности электрода составляет миллисекунды - намного меньше, чем требуется для их полного окисления, поэтому степень превращения составляет лишь около 1-5\% [4]. Таким образом, при амперометрическом детектировании регистрируется изменение тока $\boldsymbol{i}$, протекающего через ячейку, обусловленное изменением концентрации анализируемого вещества [4]. Эта обусловленность определяется кинетикой процесса окисления, которая в простейшем случае определяется дифференциальным уравнением 1-го порядка:

$$
i \approx \frac{d C}{d t}=k C
$$

где $C$ - концентрация молекул антиоксиданта в растворе, $t$ - время реакции, $k$ - константа скорости реакции.

Можно согласиться с тем, что амперометрический метод позволяет получать информацию обо всех

Бирюков Валентин Васильевич - директор института промышленной биотехнологии, доктор технических наук, профессор, тел.: (499)-267-07-28, e-mail: birval@rambler.ru антиоксидантах в пробе [4], поскольку каждый антиокислительный компонент обеспечивает вклад в суммарный поток электронов: 


$$
i \approx \frac{d C_{1}}{d t}+\frac{d C_{2}}{d t}+\frac{d C_{3}}{d t}+\cdots+\frac{d C_{n}}{d t}
$$

где $C_{1}, C_{2}, C_{3} \ldots . . C_{n}$ - концентрации различных антиоксидантов в пробе. Однако из этого не следует, что суммарный ток пропорционален сумме концентраций антиоксидантов, поскольку константы скоростей окисления различных антиоксидантов различны:

$$
i \approx k_{1} C_{1}+k_{2} C_{2}+k_{3} C_{3}+\ldots+k_{n} C_{n},
$$

где $k_{1}, k_{2}, k_{3} \ldots k_{n}$ - константы скорости окисления антиоксидантов $C_{1}, C_{2}, C_{3}, \ldots C_{n}$ соответственно. Предположение о возможности измерения суммарно всех антиоксидантов при амперометрическом детектировании базируется на молчаливом (но неверном) допущении, что константы скорости окисления различных антиоксидантов равны:

$$
k=k_{1}=k_{2}=k_{3}=\cdots=k_{n},
$$

откуда вытекает, что ток при амперометрическом детектировании в этом случае был бы пропорционален сумме концентраций антиоксидантов:

$$
i \approx k\left(C_{1}+C_{2}+C_{3}+\ldots C_{n}\right)
$$

В то же время известно, что антиоксиданты бывают быстро и медленно окисляемые, так что величины констант окисления могут существенно различаться. И тогда определение их суммарной концентрации по формуле (5) дает систематическую погрешность, величина которой зависит от того, насколько сильно различаются индивидуальные константы скорости для различных антиоксидантов.

Здесь следует остановиться на существенном различии понятий, которые иногда считают синонимами [1], а именно - «антиоксидантная активность» (antioxidant activity) и «антиоксидантная емкость» (antioxidant capacity). Первое из них характеризует суммарную скорость окисления в данный момент времени независимо от того, какие антиоксиданты - короткоживущие «быстрые» или долгоживущие «медленные» создают эту суммарную скорость. В этом случае ток амперометрического детектора определяется уравнением (3), и, следовательно, именно этот параметр правильно определяется при амперометрическом детектировании.

Второе понятие - антиоксидантная емкость - не скорость окисления в данный момент времени, а общее количество вещества антиоксиданта, которое может быть окислено (т.е. суммарная концентрация антиоксидантов). Покажем, что использование амперометрического метода для определения этого параметра сопряжено с погрешностями.

В таблице представлено несколько вариантов смесей с разным соотношением двух типов антиоксидантов - «медленного» с константой скорости окисления $\boldsymbol{k}_{\boldsymbol{l}}=\boldsymbol{k}$ и «быстрого» с константой скорости $\boldsymbol{k}_{2}=\mathbf{3} \boldsymbol{k}$. Соответственно концентрации этих антиоксидантов в смеси обозначены как $\boldsymbol{C}_{\boldsymbol{I}}$ и $\boldsymbol{C}_{2}$, а токовый сигнал амперометрического детектора вычислен по формуле $\boldsymbol{i}=\boldsymbol{k} \boldsymbol{C}_{\boldsymbol{l}}+\mathbf{3} \boldsymbol{k} \boldsymbol{C}_{\mathbf{2}}$.

В первых пяти вариантах таблицы (№1-5) суммарная концентрация антиоксидантов принята постоянной $(1,0 \boldsymbol{C})$, но соотношение компонентов - разное. Токовый сигнал детектора при этом существенно различается (в 1,4-3 раза). Очевидно, что отличия будут тем больше, чем больше различаются кинетические константы окисления. Следующие 5 вариантов (№6-10) рассчитаны таким образом, чтобы амперометрический сигнал был одинаков $(3,0 \boldsymbol{k}$ ). При этом различалась суммарная концентрация антиоксидантов (в 1,67-3 раза). Общий вывод из проведенного анализа таков: амперометрический метод вполне подходит для определения антиоксидантной активности (суммарной скорости окисления), но может давать существенные погрешности при измерении суммарной концентрации антиоксидантов, особенно если их кинетические характеристики сильно различаются. Метод может быть использован только в тех случаях, если речь идет об объекте измерения, в котором антиоксидантную активность проявляет одно вещество или группа веществ с близкими кинетическими характеристиками. 
Значения токового сигнала амперометрического детектора при различных соотношениях концентрации в растворе антиоксидантов с различной кинетикой окисления

\begin{tabular}{c|c|c|c|c}
\hline № & $\begin{array}{c}\text { Концентрация «медлен- } \\
\text { ного» антиоксиданта } \boldsymbol{C}_{\boldsymbol{I}}\end{array}$ & $\begin{array}{c}\text { Концентрация «быстро- } \\
\text { го» антиоксиданта } \boldsymbol{C}_{\boldsymbol{2}}\end{array}$ & $\begin{array}{c}\text { Суммарная концентрация } \\
\text { антиоксидантов } \boldsymbol{C}_{\boldsymbol{I}}+\boldsymbol{C}_{\boldsymbol{2}}\end{array}$ & $\begin{array}{c}\text { Токовый сигнал детектора } \\
\boldsymbol{i}=\boldsymbol{k} \boldsymbol{C}_{\boldsymbol{I}}+3 \boldsymbol{k} \boldsymbol{C}_{2}\end{array}$ \\
\hline 1 & 0 & $1,0 \boldsymbol{C}$ & $1,0 \boldsymbol{C}$ & $3,0 \boldsymbol{k}$ \\
2 & $0,2 \boldsymbol{C}$ & $0,8 \boldsymbol{C}$ & $1,0 \boldsymbol{C}$ & $2,6 \boldsymbol{k}$ \\
3 & $0,5 \boldsymbol{C}$ & $0,5 \boldsymbol{C}$ & $1,0 \boldsymbol{C}$ & $2,0 \boldsymbol{k}$ \\
4 & $0,8 \boldsymbol{C}$ & $0,2 \boldsymbol{C}$ & $1,0 \boldsymbol{C}$ \\
5 & $1,0 \boldsymbol{C}$ & 0 & $1,0 \boldsymbol{C}$ & $1,0 \boldsymbol{k} \boldsymbol{C}$ \\
6 & 0 & $1,0 \boldsymbol{C}$ & $1,0 \boldsymbol{C}$ & $3,0 \boldsymbol{k} \boldsymbol{k}$ \\
7 & $1,0 \boldsymbol{C}$ & $0,67 \boldsymbol{C}$ & $2,0 \boldsymbol{C}$ & $3,0 \boldsymbol{k}$ \\
8 & $1,5 \boldsymbol{C}$ & $0,5 \boldsymbol{C}$ & $2,33 \boldsymbol{C}$ & $3,0 \boldsymbol{k} \boldsymbol{C}$ \\
9 & $2,0 \boldsymbol{C}$ & $0,33 \boldsymbol{C}$ & $3,0 \boldsymbol{C}$ & $3,0 \boldsymbol{k}$ \\
\hline
\end{tabular}

Оценивая антиоксидантную способность природных или искусственных веществ, следует четко понимать, что именно является важным в данной ситуации - собственно суммарная антиокислительная способность (емкость) вещества, которая проявляет себя в течение длительного времени или максимально возможная скорость антиокисления с первых минут его применения. На этот вопрос должны отвечать врачи и специалисты по питанию человека (если речь идет о пищевых антиоксидантах).

Имеются аналогии в биотехнологии. Например, концентрация ферментов оценивается только по скорости протекания катализируемых ими реакций. Наоборот, величина БПК (биохимическая потребность в кислороде для загрязненных вод) определяется после проведения длительного цикла биоокисления, вплоть до полного завершения потребления субстрата.

Амперометрический метод можно модифицировать для определения антиокислительной емкости, если перейти к периодическому (а не проточно-инжекционному) методу контроля. В таком методе доза образца должна находиться в ячейке (или в циркуляционном контуре) до тех пор, пока ток (сигнал детектора) не снизится до нулевого. Затем проводится определение площади под кривой «ток - время» и общее количество электричества, затраченное на окисление дозы антиоксиданта. Но это уже кулонометрический метод, имеющий важный недостаток - длительный цикл измерения.

\section{Bblводbl}

Амперометрический метод может быть сопряжен с большими погрешностями измерения в случае суммарного определения концентрации (антиоксидантной емкости) образцов, содержащих смесь антиоксидантов с разными кинетическими характеристиками (медленно и быстро окисляемых антиоксидантов). Точно так же этот метод не может использоваться для сопоставления антиоксидантной емкости чистых продуктов, имеющих разные кинетические характеристики.

\section{Список литературы}

1. Яшин Я.И., Яшин А.Я. Проблема определения концентрации антиоксидантов // Компетентность. 2009. №8. C. 50-53.

2. Яшин А.Я. Новый прибор «ЦветЯуза-01-АА» для определения суммарного содержания антиоксидантов в пищевых продуктах, БАДах // Мир измерений. 2008. №2. С. 45-48.

3. Федина П.А., Яшин А.Я., Черноусова Н.И. Определение антиоксидантов в продуктах растительного происхождения амперометрическим методом // Химия растительного сырья. 2010. №2. С. 91-97.

4. Федина П.А. Приборное и методическое обеспечение автоматизированного определения водо- и жирорастворимых антиоксидантов : дис. ... канд. техн. наук. М., 2011. 162 с. 
Biryukov V.V. PECULIARITIES OF ANTIOXIDANT CONCENTRATION MEASUREMENT BY THE AMPEROMETRIC METHOD

Moscow State University of Environmental Engineering, ul. Staraia Basmannaia, 21/4, Moscow (Russia), e-mail: birval@rambler.ru

The analysis of metrological characteristics of the amperometric antioxidant measuring method is carried out. It is confirmed, that the amperometric method makes it possible to determine correctly an antioxidant activity (the total rate of oxidation reactions). On the other hand, the use of this method for the indirect measuring the antioxidant capacity (the total antioxidants concentration) may result in sufficient measurement errors. kinetics.

Keywords: Antioxidants, antioxidant activity, antioxidant capacity, amperometric detecting, oxidation rate, oxidation

\section{References}

1. Iashin Ia.I., Iashin A.Ia. Kompetentnost', 2009, no. 8, pp. 50-53. (in Russ.).

2. Iashin A.Ia. Mir izmerenii, 2008, no. 2, pp. 45-48. (in Russ.).

3. Fedina P.A. , Iashin A.Ia. , Chernousova N.I. Khimiia rastitel'nogo syr'ia, 2010, no. 2, pp. 91-97. (in Russ.).

4. Fedina P.A. Pribornoe i metodicheskoe obespechenie avtomatizirovannogo opredeleniia vodo- $i$ zhirorastvo-rimykh antioksidantov: dis. ... kand. tekhn. nauk. [Instrumentation and methodological support of the automated determination of water and fat-soluble antioxidants: Cand.Tech.Sci thesis.]. Moscow, 2011, 162 p. (in Russ.).

Received June 12, 2012 